\title{
Well-being, Disability, and Choosing Children
}

\author{
Matthew J. Barker \\ Concordia University, Montréal, Canada \\ matthew.barker@concordia.ca \\ Robert A. Wilson \\ La Trobe University, Melbourne, Australia \\ rwilson.robert@gmail.com
}

\begin{abstract}
The view that it is better for life to be created free from disability is pervasive in both common sense and philosophy. We cast doubt on this view by focusing on an influential line of thinking that manifests it. That thinking begins with a widelydiscussed principle, Procreative Beneficence, and draws conclusions about parental choice and disability. After reconstructing two versions of this argument, we critique the first by exploring the relationship between different understandings of well-being and disability, and the second by focusing briefly on the idea of a significant reason. By placing these results within the broader historical and ongoing contexts in which the lives of those with disabilities have been deemed of inferior quality, we conclude with a call for greater humility about disability and well-being in thought and practice.
\end{abstract}

\section{The disability-free intuition}

You are going to create a child. There is no actual child yet, so none you could benefit or harm now. You simply get to choose which possible child will later become actual. You are told you have two options and are given just this information about them: selecting the first option will very probably lead to a child with a recognized disability, while selecting the second will very probably lead to a child with no disabilities whatsoever. Which option should you choose? (Cf. Savulescu 2001, p. 414.)

You probably want more information before you give a final answer. But most of you (certainly not all) will also believe the existing information gives an initial and significant moral reason-one to weigh against others - to choose the second option. The pervasive thought is that it is better to create lives free from disability. Call this the disability-free intuition. 
This common sense intuition is manifest in otherwise diverse philosophical discussions cast in terms of an individual's well-being-what is good for that individual (for example, Savulescu and Kahane 2009; Brock 2005; McMahan 2005; Singer 2001; Kitcher 1997; and Parfit 1987). Despite the ubiquity of the disability-free intuition, it is mistaken. In this paper we offer a novel argument in support of this claim. While building on past criticisms of the disability-free intuition that stem from specific considerations about disability (for example, Amundson 2005; Goering 2008; Parens and Asch 1999; and Sparrow 2008) and about its relationship to well-being (for example, Barnes 2009a, 2009b, and 2014), we also develop more general points about well-being, identifying an unacknowledged hubristic universalism about levels of well-being that pervades the philosophical literature on well-being and disability. Recent philosophical work has made a convincing case against the value-neutrality of appeals to well-being (Alexandrova 2017), and we view our argument as comporting with that general view.

Our strategy is to focus on a line of argument that has been particularly influential in bioethics, the conclusion of which manifests a specification of the disability-free intuition. This target argument begins with a widely-discussed principle called Procreative Beneficence that articulates a putatively general, parental obligation in creating a child. After carefully reconstructing two versions of the argument $(\$ 2)$, we critique the first by exploring the relationship between well-being and disability $\left(\$_{3}\right.$ and $\$_{4}$ ) and the second by focusing more briefly on the idea of a significant reason $(\$ 5)$. Our claim about hubris in philosophical discussions of disability and well-being, and our countering call for humility, become more poignant when considered within the broader historical context of past eugenic practices that targeted those deemed to have lives of inferior quality, together with the ongoing influence of those discussions and practices in the lives of people with disabilities (\$6).

\section{From procreative beneficence to disability-free procreation}

Two of the most prominent defenders of Procreative Beneficence, Julian Savulescu and Guy Kahane, express that principle as follows:

If couples (or single reproducers) have decided to have a child, and selection is possible, then they have a significant moral reason to select the child, of the possible children they could have, whose life 
can be expected, in light of the relevant available information, to go best or at least not worse than any of the others. (Savulescu and Kahane 2009, p. 274; see also Savulescu 2001, 2007, and 2008, Kahane and Savulescu 2009, and Savulescu and Kahane 2011.)

\subsection{Procreative beneficence: our aims}

Despite Procreative Beneficence's influence, challenges to it range from appeals to acceptable thresholds of well-being (for example, Asch and Wasserman 2005; Herissone-Kelly 2006) and the rationality of random selection (Benatar and Wasserman 2015, p. 218), to the well-known 'expressivist critique' of selective termination (for example, Parens and Asch 1999).

Although we share reservations about the truth of Procreative Beneficence itself, we want to show that those who apply the principle can also be challenged on their own terms. So we provisionally grant Procreative Beneficence and focus instead on clarifying and then challenging reasoning that cascades from it. Although our argument could be readily adapted to counter analogous reasoning about other traits (for example, sex), we focus on the case of disability.

\subsection{Procreative beneficence: some clarifications}

We follow the common practice of understanding a life's going best in terms of well-being, and relative to the other lives that could have been selected. In these terms, Procreative Beneficence says that when selecting among possible children, parents have a significant moral reason to select the one with the highest expected well-being (or one with expected well-being no lower than any other).

Procreative Beneficence is 'a species of decision-theoretic consequentialism' (Savulescu 2008, p. 58). As such, it compares probable (rather than guaranteed) levels of future well-being when considering the expected well-being of possible children who become actual. Such probabilities take account of contextual factors and the principle directs us to consider our current and foreseeable world, with all its predictable vagaries and injustices, rather than the expected wellbeing of future people in far-off worlds (Savulescu and Kahane 2009).

Procreative Beneficence need not be tied to especially controversial types of selection. In many places some prospective parents choose to create a child through in vitro fertilization (IVF). In consultation with a physician, they often select which of the produced embryos to implant into the womb of the prospective mother or surrogate. Before 
implantation, they can also use preimplantation genetic diagnosis (PGD) to detect chromosomal and genetic features that are usually viewed as correlating positively or negatively with expected well-being. PGD has been used to detect sex chromosomes, genes for deafness, genes for autosomal recessive disorders (for example, cystic fibrosis, Beta-thalassemia, and type 1 spinal muscular atrophy), genes for autosomal dominant disorders (for example, Huntington's Disease and myotonic dystrophy), and chromosomal conditions such as Trisomy 21 (Down syndrome).

In such a context, Procreative Beneficence putatively directs parental decision-making about which embryo(s) to implant. A simple case can show how the significant moral reasons that Procreative Beneficence is said to yield derive partly from more specific ones concerning each type of trait for which relevant information is available (Savulescu 2001; Savulescu and Kahane 2009).

Suppose that Alison, a prospective parent, has completed IVF and learned all the relevant available information to emerge from PGD. The information says that two embryos, $\mathrm{A}$ and $\mathrm{B}$, are viable; she will choose one, having decided that choosing neither is not an option for her. The information also addresses particular traits, saying that embryo B will probably develop a type of trait typically thought to substantially reduce expected child well-being, while A probably will not develop that trait. To stay focused on the implications of Procreative Beneficence, also suppose that the expected well-being of both potential children is above some threshold level. Then, specific to the type of trait that B will probably develop, Procreative Beneficence implies that Alison has a significant moral reason to select A instead.

\subsection{A trait type version of Procreative Beneficence}

Being concerned with probabilities as noted, Procreative Beneficence will have this implication for any trait that, according to the relevant information about actual instances of that trait in current contexts and future instances in foreseeable contexts, substantially reduces wellbeing in most of its known cases (Brock 2005, pp. 73-4). Thus we get a trait type implication of Procreative Beneficence:

Trait Type Principle: If most instances of a trait reduce well-being substantially, then prospective parents typically have a significant moral reason to select against creating a child who will probably develop that trait, provided they could instead create a child who probably will not develop that trait. 
Note that the broad scope of this principle implies that it is not restricted to 'severe disease traits'. It would apply as much to being female or to being an asthmatic, if the relevant available information suggested that being female or having asthma significantly reduces expected child well-being compared to the other available selection options. (See Savulescu 2001.)

\subsection{Two disability implications of Procreative Beneficence}

The type of trait we are interested in, however, is having a recognized disability - a paradigmatic disability as understood in the everyday sense, such as being deaf, being blind, or being intellectually subnormal. Many paradigmatic disabilities are sometimes thought of as 'physical disabilities', but note that paradigmatic disabilities may involve sensory and cognitive departures from the norm that are not always best thought of as bodily in nature. By 'disability' we mean all these sorts of paradigmatic disabilities. Disability so understood does and will continue to play crucial roles in how prospective parents, clinicians, technicians, administrators, and policy makers implicitly or explicitly deploy Procreative Beneficence. Thus, when the Trait Type Principle is narrowed from any type of trait to disability in particular we get:

Modest Disability Principle: If most disabilities reduce well-being substantially, then prospective parents typically have a significant moral reason to select against creating a child who will probably develop a disability, provided they could instead create a child who probably will not develop that disability.

The antecedent of the Modest Disability Principle-the empirical claim that most disabilities reduce well-being substantially-is so pervasive in both common sense and ethics that Ron Amundson has called it the 'Standard View' (Amundson 2005, p. 103).

Proponents of Procreative Beneficence may not insist on substantial reduction here, claiming instead that well-being reduction of any amount suffices to generate the significant moral reason in question, so long as such reduction is true of most disabilities. This may, for instance, be what Savulescu and Kahane are suggesting when they say that 'somewhat smaller prospects of well-being' give 'parents reasons not to select' (Savulescu and Kahane 2009, p. 290). This would extend the moral reach of Procreative Beneficence via the following logically stronger disability implication:

Bold Disability Principle: If most disabilities reduce well-being to any degree, then prospective parents typically have a significant 
moral reason to select against creating a child who will probably develop a disability, provided they could instead create a child who probably will not develop that disability.

A number of prominent authors at least tacitly draw on one or the other of these two disability implications of Procreative Beneficence. Brock, for example, does so (Brock 2005, pp. 73-4) when arguing that a policy of preventing disability through genetic prenatal screening is justified. Savulescu does so when claiming that Procreative Beneficence implies that 'if we have two embryos which in all respects appear to be the same, except B has a state which is a [recognized] disability, then we have a strong reason to choose A' (Savulescu 2008, p. 52).

Finally, since both versions of the Disability Principle are about how recognized disabilities influence well-being in our actual and foreseeable social contexts, their proponents could embrace the Standard View while recognizing that well-being reductions correlated with such disabilities often derive from the non-inclusive social structures and practices ubiquitous in society. Thus they could also agree with what Elizabeth Barnes has called the mere-difference view, which says that 'having a disability makes you physically non-standard, but it doesn't (by itself or automatically) make you worse off' (Barnes 2016b, p. 55). ${ }^{1}$

\subsection{Our strategy clarified}

Variants of the Standard View plus either the Modest Disability Principle or the Bold Disability Principle lead to a claim that gives an exacting voice to the disability-free intuition:

Disability-Free Procreation: Prospective parents typically have a significant moral reason to select against creating a child who will probably develop a disability, provided they could instead create a child who probably will not develop that disability.

Table 1 summarizes two versions of the modus ponens argument we have, in effect, articulated on behalf of those taking the road from Procreative Beneficence to Disability-Free Procreation.

Table 1 reveals the more ambitious premise in each version of the argument. In Version $\mathrm{A}$, the more ambitious claim is the second

\footnotetext{
${ }^{1}$ For introduction of the mere-difference view, see Barnes (2014), and for ongoing disagreement about both how to articulate it and whether it is true, see Barnes (2016a) and Kahane and Savulescu (2016).
} 
Table 1. Two versions of the Argument for Disability-Free Procreation

\begin{tabular}{ll}
\hline $\begin{array}{l}\text { Argument for Disability-Free } \\
\text { Procreation }\end{array}$ & $\begin{array}{l}\text { Argument for Disability-Free } \\
\text { Persion A }\end{array}$ \\
Version B
\end{tabular}

premise, the Standard View, which is combined with a less ambitious first premise, the Modest Disability Principle. Version B of the argument replaces the Standard View with a less ambitious second premise, accordingly strengthening the first premise to form the more ambitious Bold Disability Principle. We will argue that both arguments fail because each of their more ambitious premises is false.

In short, even granting Procreative Beneficence, one cannot derive Disability-Free Procreation, a conclusion about parental choice and disability that articulates the disability-free intuition. We turn next to Version A of the target argument and our two-part case against the Standard View, concentrating first on subjective well-being $\left(\$_{3}\right)$ and then on objective well-being $(\$ 4)$.

\section{The case against the Standard View: subjective well-being}

Empirical researchers distinguished subjective from objective wellbeing in the 1980s, partly because they realized that then-prevailing models of disability (for example, those models provided by the World Health Organization (1980) and by Nagi (1976)) did not 
adequately account for the subjective experiences of persons with disabilities. Emerging views (Diener 1984; Lawton 1984; Stock, Okun, and Benin 1986) held that a person's subjective well-being over some duration of time is how well that person experiences life to be going over that period; this was also frequently called subjective quality of life (QOL) and the authors we cite who use that term can be understood as referring to the same thing (see Camfield and Skevington 2008). Commonly measured components of subjective well-being have included happiness, life satisfaction, and positive affect or morale (Fuhrer et al. 1992). Multiple validated scales are now readily available for measuring each component, with life satisfaction being one of the most often measured.

When asked via such measures, most disabled people report only slightly lower QOL than most non-disabled people. Yet as Ron Amundson has noted, most non-disabled people hold a belief in tension with this; they think that disabilities 'have a very strong negative impact on the quality of life of the individuals who have them' (Amundson 2005, p. 103). To resolve these differing assessments, we further develop Amundson's epistemic challenges to the Standard View by clarifying the distinction between subjective and objective well-being and how that distinction uncovers the depth of the challenges and the radical limits to 'our' knowledge of disability.

First, the all too common claim that non-disabled onlookers have a more accurate window into the subjective well-being of disabled people than do those people themselves reflects the same sort of hubris we now identify in bygone claims that men have a more accurate understanding of the subjective well-being of women than women themselves do, or that 'first world' people enjoy such a vantage point with respect to the subjective well-being of people in the 'developing world'. This alone should suffice for us to have more humility about 'our' views of well-being and disability. Yet the tendency for nondisabled people to severely underestimate the subjective well-being of disabled people is so entrenched within philosophy that we summarize some of the relevant empirical findings.

Fuhrer and colleagues measured life satisfaction in a cross-sectional study of persons living with spinal cord injury (SCI), including persons having SCI from birth. Their 'findings by no means indicate that people with SCI are uniformly less satisfied with their lives than are people generally' (Fuhrer et al. 1992, p. 555), discovering no statistically significant association between measures of life satisfaction and measures of extent of paralysis, nor between measures of life 
satisfaction and neurological classification recommended by previous studies. In short, people suffering spinal injuries typically do not report significantly lower quality of life than other people. The same appears true of those with everyday disabilities related to vision, hearing, intellect, and mental health; Menhart et al. (1990) found that people with conditions of these latter sorts typically reported even greater life satisfaction than those with more physical disabilities.

In an earlier study of mobility-disabled persons without SCI, Stensman (1985) found little difference between their mean ratings of subjective QOL and those of a non-disabled control group (cf. Fuhrer et al. 1992, p. 555). Focused on just intellectual disability, a more recent study found that when subjects with epilepsy also had intellectual disabilities, they tended to have higher subjective QOL than those without the intellectual disabilities (Endermann 2013, p. 193). This effect of intellectual disabilities seemed relatively independent of having epilepsy, as the more physical epilepsy variables 'such as seizure frequency...did not affect global [that is, subjective] QOL' (Endermann 2013, p. 194). Perhaps more strikingly, Padua et al. (2002) found that the more that persons with spina bifida were disabled, the higher they tended to score on components of subjective QOL.

The above studies all examined subjective well-being during relatively narrow time slices in the lives of disabled persons. Longitudinal data on subjective well-being is less plentiful, but exists. Gow et al. (2005) made use of the Lothian Birth Cohort 1921, a group of 550 older people whose mental abilities had already been assessed at mean ages 10.9 and 79.1 years. The researchers found that cohort members' satisfaction with life at about age 80 'was unrelated to IQ in either childhood or late adulthood' and unrelated 'to cognitive change in their lifetime' (Gow et al. 2005, p. 142). So in this cohort, being less cognitively able than others at an early age did not predict lower life satisfaction later; being less cognitively able at the later age also did not matter to life satisfaction at that age, and neither did drops in cognitive ability over a lifetime. The conclusions from this longitudinal study comport with Diener's (1984) earlier finding that life satisfaction 'does not seem to be related to current cognitive ability' (Gow et al. 2005, p. 141). ${ }^{2}$

\footnotetext{
${ }^{2}$ Although some studies find reduced life satisfaction levels after acquiring a severe disability (for example, Lucas et al. 2003), they are not directly relevant to typical cases of procreative selection because the disabilities typically at issue during procreative selection are ones that a person has from birth. See also Lucas (2007) for an influential analysis of two
} 
Thus these empirical studies cut across the divisions between disabilities that are 'physical' and 'cognitive', and those that range from shorter to longer durations of focus. Such studies are currently the best grounds that non-disabled people have for forming beliefs about the relative subjective well-being of disabled people-far better than their intuitions based on introspection and limited interpersonal experiences with disabled people. Beyond such intuitions, there is no good reason to believe that people with varying disabilities-spina bifida, people with epilepsy, people who are deaf, people with subnormal IQ, people with low mobility, and so on-all tend toward mistaken assessments of their own subjective well-being. Importantly, a sceptic here cannot support her view by claiming that many disabled people have higher-than-expected subjective wellbeing merely because they have formed preferences and goals that are objectively suboptimal. That would simply be a change in subject: from a question about subjective to objective well-being. (The same is true of the claim that disabled people reporting high subjective well-being fail to appreciate the challenges their disabilities pose.) ${ }^{3}$

We suspect that not only the Standard View but also lingering doubts about the empirical studies manifest a two-fold hubris about disability and well-being, encompassing both the difficulty of appreciating how life is experienced by others who happen to have a disability (Amundson 2005; Moller 2011) and the meta-difficulty of recognizing and addressing the extent of the first difficulty (Ubel et al. 2005, p. S61). We return to such suspicions and doubts in $\$ 4$, where we will argue that disability hubris also pervades discussions of objective well-being.

longitudinal studies cast in terms of 'hedonic adaptation' that argues for both significant drops in happiness following the onset of disability and a failure in hedonic adaptation, and Powdthavee (2009) and Pagán-Rodriguez (2010) for alternative analyses. Likewise, we set aside cases in which a disability results in, or is constituted by, high, continuous levels of pain over long periods-where one would expect reports of subjective well-being to be low-since they represent a special case and are not representative of most disabilities.

${ }^{3}$ As the editors have helpfully pointed out, the majority of the relevant work on subjective well-being relies on methods, such as surveys or questionnaires, that presuppose a certain level of cognitive sophistication, and so they may limit what conclusions we can draw about wellbeing in those without that sophistication. Some may take this as a reason to expect current methods to overestimate well-being in people with disabilities. But in accord with the general argument we are making, including specific epistemic obstacles we identify, we would encourage more humility about what to infer about disability and well-being from this methodological limitation. 


\section{The case against the Standard View: objective well-being}

The standard example of a hypothetical happy slave is often taken to suggest that there is more to well-being than how one feels, exemplifying that subjective well-being may be high while objective wellbeing is low. If our conclusions about subjective well-being are correct, the next question relevant to evaluating Version A of the Argument for Disability-Free Procreation concerns this alternative conception of well-being: should we believe that most disabilities reduce objective well-being substantially?

The answer depends on which activities, states, and so on, we believe are constitutive of-components of-objective well-being. Consider three components that Dan Brock has posited in his support for the Standard View about objective well-being:

- ability to perform major life activities, such as walking and seeing;

- a relatively high level of mobility;

- a significant degree of social and political liberty. ${ }^{4}$

To argue that we should not believe most disabilities reduce objective well-being substantially, we distinguish two ways of conceiving of the relationship between objective and subjective well-being. On either conception, problems arise for typical identifications of components of objective well-being. It is not merely that it is hard, in usual or otherwise mundane ways, to figure out what the components are. Rather, by uncovering and reflecting on the relevant counterfactuals, standpoint biases, and the structure of well-being, we argue that each conception of objective well-being throws up distinct and decisive epistemic obstacles to the claim that most disabilities substantially reduce objective well-being.

\subsection{Dependent objective well-being}

On the first conception, causation takes central importance, as it does in the constitution of many scientific categories (Boyd 1999). The constitutive components of objective well-being are the main causal

\footnotetext{
${ }^{4}$ Brock (1995) presumes the first criterion when discussing the Americans with Disabilities Act (Amundson 2005). He states the second criterion when interpreting the Health Status Index (HSI) as measuring constitutive components of objective well-being (Brock 1993). And he implies something like the third when deploying a version of the happy slave example (Brock 2005).
} 
factors of the subjective well-being of people, regardless of whether people are aware of (or confused about) those factors being the typical causes of subjective well-being. Some authors propose the above mobility criterion in this way when positing that relatively high mobility is a main causal enhancer of subjective QOL (for example, Brock 1993). (For such authors, this putative objective causal relationship is claimed to hold despite the failure of some people with low mobility to appreciate this in their self-reported QOL.) Because the requisite notion of objective well-being is dependent on typical main causal connections with subjective well-being, we call it 'dependent objective well-being' (DOW).

No doubt, a few disabled people sometimes over-report their own subjective well-being partly by not accurately dwelling on how their low mobility really, objectively, causes reduction in their subjective QOL. But when the subjective QOL reports of many people with mobility-related disabilities suggest that low mobility typically does not cause large net reductions in their subjective well-being, this should be interpreted as strong evidence that low mobility is not, objectively, a large draw on subjective well-being, that is, it is not a component of DOW. There are many such reports, some gathered in the Stensmen study cited above. (See also Domellöf, Hedlund, and Ödman 2013.) Studies of other disabilities and variables have found similar contrary evidence by different means, using measures of health-related quality of life in which the physical variables are thought of as components of what we term DOW (Gavelova et al. 2015; Endermann 2013, p. 193). More generally, given the study results described in $\S_{3}$ it is very probable that disabled and non-disabled people score similarly on whichever variables really are the main causal enhancers of subjective well-being, even if these are similar scores on different variables. Two of the enhancers hypothesized to be especially important for many disabled people, based on investigations of contextual interactions between variables of quality of life using conditional independence graphs, are being in close relationships (for example, being married) and having social support (Fellinghauer et al. 2012). Since such enhancers just are the components of DOW, we should reject the view that most disabilities substantially reduce such well-being.

The contrary view, held perhaps by the non-disabled person in the street as well as by prominent philosophers (for example, Brock 1993, p. 309), does not sufficiently appreciate the relevant experiences of and data about disabled persons (cf. Goering 2008; Amundson 2005), as we 
suggested was the case for subjective well-being. We further elaborate on the operation of such hubris by detailing two limitations of imagination that we believe fuel it.

The first turns on the multiple realization of subjective well-being. There are many different paths to experiencing a well-lived life, and these vary in their degree of overlap. Factors like mobility, for instance, may be objectively large causal factors shared by many but not all paths to subjective well-being; on other paths, people with low mobility often find alternative ways to achieve subjective wellbeing, and so low mobility becomes a small factor. We are all prone to misjudge which factors are objectively the main causal influences on the subjective well-being of others, especially when our first-person paths to subjective well-being diverge.

The second turns on a mistake in what we imagine. For a nondisabled person, especially someone with limited shared experiences with disabled people, it is tempting to rely on the following sort of counterfactual when thinking about the objective influences on subjective well-being:

If I, a very mobile non-disabled person, became disabled in a way that significantly reduced my mobility, this reduced mobility would probably significantly reduce my subjective well-being.

Much research indicates that this counterfactual is true for many nondisabled people (for example, Lucas 2007). The counterfactual encourages them to consider losing something (high mobility) they have come to subjectively value through their experience, and then imagine losing that. Yet this makes the counterfactual distorting in the present context because we are focusing on disabilities that are predictable (by methods such as PGD) prior to birth, and these typically (though not always) are early-onset, lifelong states of being. A person with reduced mobility of this sort typically never directly experienced mobility, and so never lost it. For her, low mobility is a state that has simply always been, as Deborah Kent says of her blindness, a 'part of the background music that accompanied [her] life' (Kent 2000, p. 57). The counterfactual's antecedent thus focuses on the wrong candidate objective cause of significantly reduced subjective well-being. The relevant counterfactuals — of the form 'If I had had limited mobility from birth, my subjective well-being would probably have been significantly lower' - are significantly more complicated, and very likely better assessed by deferring to the views of people with the relevant lived experience of disability. We suggest that the same is true of late-onset 
conditions, such as Huntington's disease or age-related dementia, where intuitions about loss are probably widely shared but may not be reliable guides to post-transitional subjective well-being.

\subsection{Independent objective well-being}

Call well-being whose components needn't typically cause or constitute subjective well-being 'independent objective well-being' (IOW). Note that this characterization of IOW does not rule out that components of an agent's IOW must be valued by that agent (for example, see Glover 2008) nor that subjective well-being may itself be a component of IOW, as some objective list theorists have argued (see, Crisp 2014).

General problems in identifying the constitutive components of IOW have been recognized in claims of the putative cultural parochialism of perhaps the best-known attempt to enumerate and ground the objective goods necessary for human flourishing: Martha Nussbaum's version of the capabilities approach (for example, 2001). Problems of identifying the constitutive components of IOW are especially acute in the context of the experiential variability between disabled and non-disabled persons. If well-being is to be assessed in terms of individual capabilities independent of that individual's subjective reports, this approach to well-being is prone to dismiss the well-being of those lacking designated individual capabilities, such as those associated with any of the five senses, or bodily integrity, or physical health. (Also see Barnes 2009a.) This is so despite Nussbaum's own attempts (for example, Nussbaum 2009) to apply the capabilities approach to disability (Wasserman et al. 2016).

On the dependent conception of well-being, identifications from non-disabled people proved unreliable because they were not informed appropriately by the views of disabled people. On the independent conception, by contrast, such identifications are impossible because no people-non-disabled or disabled-are in the relevant epistemic position. Or so we will argue.

The process of correctly identifying a component, X, of independent well-being can be thought of as involving the posing of the following counterfactual to oneself:

Even if $\mathrm{X}$ were to cause no effect in my subjective well-being, $\mathrm{X}$ would nonetheless contribute to my objective well-being.

There may be near universal agreement about such counterfactuals when we consider political values such as various freedoms, including 
(say) freedom from physical constraint. But such agreement dissolves, for good reason, once we turn to traits that correspond to bodily, lived conditions that vary across people.

Consider walking or seeing. We think that these are valuable primarily because of their causal influence on subjective well-being in many cases, typically via their instrumental role in allowing people to achieve other goals. But suppose that they didn't have such influence. Would they still be components of well-being? Those who don't walk and those who don't see will have little trouble answering 'No' to this question; those who do walk and see will at least waver in response. Each of these responses reflects a value or bias structured by varied lived experiences. The same is true for activities characterized at coarser grains of description, such as relatively high levels of mobility and access to information, activities that might be realized by (respectively) walking or seeing.

The broader problem is that the value of many (if not all) such candidate capacities and activities clearly depends on what they are coinstantiated with, including the kinds of social environments in which they occur. Clearly, a person's being blind or sighted, or nonperambulatory or someone who walks, affects what the components of her independent objective well-being are, even if the components are not significantly causally related to her subjective well-being, and even if the person does not recognize those components as valuable (Moller 2011, pp. 197-200). Less clearly, but no less surely, the things that cluster with being blind or sighted, or non-perambulatory or someone who walks, also affect what the components of a person's independent objective well-being are. Whether one can see, for example, clusters with abilities to interact with rapidly-moving objects by monitoring visual feedback, and so affects whether participation in so-called 'contact sports', and many other popular physical activities, are components of one's independent objective well-being. While these correlations and effects are only tendential, patterns of difference between disabled and non-disabled people in these respects will thus generate patterns of difference in components of independent objective well-being.

Most importantly for present purposes, such patterns of difference affect how any agent views the value of various capacities. This makes it reasonable to believe that, for at least many recognized disabilities, there is no privileged or convergent epistemic position from which the requisite counterfactuals can be assessed. Thus, in this context, a healthy scepticism is in order for attempts to individuate candidate 
necessary or sufficient conditions for independent objective wellbeing.

\subsection{Well-being and disability-free procreation}

So whichever concept of objective well-being we choose, epistemic obstacles suggest we should not believe that most disabilities reduce objective well-being substantially. We saw this was more than a 'mere difficulty' in identifying components of objective well-being. Instead, in this context people are anchored to disparate epistemic positions in ways that provide principled reasons to be sceptical that an appeal to objective well-being will provide an independent pathway to the view that disabilities substantially reduce well-being. To support this, we identified a systematic bias in the case of dependent well-being, and pointed to features of the structure of well-being in the case of independent well-being.

Together with our previous result about subjective well-being, this suggests we should not believe that most disabilities reduce objective or subjective well-being substantially. Thus we should not believe the Standard View, which is premise (A2) in Version A of the Argument for Disability-Free Procreation.

Might one retreat to Version B of that argument? We now turn to consider, more briefly, that version, which relies not on the Standard View but a weaker replacement of it, together with what we have called the Bold Disability Principle.

\section{Against the Bold Disability Principle}

Let us simply grant premise (B2) and suppose that most disabilities do at least reduce well-being to some small degree. We target (B1), the Bold Disability Principle, by focusing on the notion of a significant reason.

\subsection{Significant reasons}

Savulescu and Kahane are clear that 'even if the expected well-being of a future child should weigh less than the expected well-being of existing children, reasons of PB [Procreative Beneficence] will still be significant reasons-reasons often strong enough to outweigh the reasons given by the interests of parents and other existing people' (Savulescu and Kahane 2009, p. 277). To exemplify this, they note that many people believe that failing to help existing deaf children to hear is 
worse than allowing a deaf child to be born instead of a hearing one. They insist, nonetheless, that the moral reason to disallow the deaf child to be born in the first place is still significant, the sort that outweighs the interests of parents and others.

Such putative significance implies practical decision-making sway. We will argue that the reasons generated by small reductions in wellbeing that we are supposing to exist should seldom hold that sway. Two considerations support this.

\subsection{Factors that vary with well-being reductions}

First, the main factor that varies directly with the significance of moral reasons yielded by the Bold Disability Principle is the degree of expected reduction in well-being: the greater that reduction, the more significant the reason. But having already rejected (A2), we are now considering just cases where that expected reduction is small, and hence the associated significance of the reason generated will very often or always be correspondingly limited.

Second, the relative significance of any one reason yielded by the Bold Disability Principle varies inversely with both the number and weight of other reasons. This inverse relationship holds even when such other reasons agree with, that is, point to the same choice as, the reason in question yielded by the Bold Disability Principle. Since these other reasons are numerous, it is unlikely that any particular reason yielded by the Bold Disability Principle is relatively significant in the way envisaged by proponents of the Argument for Disability-Free Procreation.

First consider other reasons that, putatively, $\mathrm{PB}$ yields. Recall Alison's choice between embryo A and embryo B, where there is a particular trait that B but not A is expected to have, and which slightly diminishes B's expected well-being. Suppose the trait involves a slight decrease in mobility. Accordingly, $\mathrm{PB}$ would then yield one reason against selecting $\mathrm{B}$ and in favour of selecting $\mathrm{A}$. However, Alison plans to raise her child in contexts where males usually have many advantages over females, and $\mathrm{B}$ has XY sex chromosomes while A has XX sex chromosomes. Thus in addition to the reason $\mathrm{PB}$ will yield for selecting A over B based on B's expected lower mobility, PB will also yield a reason for selecting $B$ over $A$, based on their sex differences. A great many traits will differentially influence the expected well-being of the two embryos in these (often small) ways. So PB will yield a great many reasons additional to the one based on B's lower mobility. With 
so many other $\mathrm{PB}$ reasons yielded, the significance of the particular $\mathrm{PB}$ reason based in B's slightly lower mobility diminishes.

But reasons independent of Procreative Beneficence will diminish the significance of any particular disability-related reason the most, because many of those independent reasons will be relatively weighty. Prospective parents will have many desires and preferences concerning their own lives and how they care and provide for their children. When small reductions in expected well-being are considered separately from these parental reasons, they are likely to pale in significance. This is not least because the interests and well-being of prospective parents are actual, and the levels of expected well-being in possible children are not.

It is true that procreative choices of the sorts we are considering can cause the aggregate level of well-being in a population to be different than it would have been had alternative choices been made. But as aficionados of the non-identity problem know well, such differences between the actual and hypothetical levels of well-being cannot be differences for an actual individual brought into existence by the choice, because the alternative choice would have precluded that individual from having existed at all. So it is impossible for such choices to affect (improve, worsen or sustain) the level of well-being in any such individual. This impotency of such choices certainly diminishes the relative decision-making significance of any reasons yielded by the Bold Disability Principle (cf. Benatar and Wasserman 2015, p. 218) without preventing them from being moral reasons, or reasons at all. Thus while it is controversial to respond to the non-identity problem by saying that considerations of merely possible people yield no moral reasons for action at all, this is not a position we must take. ${ }^{5}$

To sum up, in actual decision-making the moral reasons the Bold Disability Principle often yields do not have the importance implied by premise (B1) in the Argument for Disability-Free Procreation.

\footnotetext{
5 Those swayed by judgments about such cases as Parfit's The Medical Programmes (Parfit 1987, p. 367) to accept his 'no difference principle', which downplays the significance of person-affecting interests, may baulk here. We think, however, that the evidential force of intuitions and judgments about such cases should be questioned at least to the extent that they reflect the biases uncovered in our paper. Elizabeth Barnes has likewise criticized distinct (though kindred) thought experiments for simply begging the question against those who believe it is not always wrong to cause a disabled child to exist when a non-disabled child could have been caused to exist instead (Barnes 2014, pp. 106-9).
} 


\section{Concluding thoughts: disability humility}

We have seen that both versions of the argument that leads from the general principle of Procreative Beneficence to Disability-Free Procreation fail, and we suspect that there is, in effect, a crucial equivocation in the chain of reasoning from Procreative Beneficence to disability-specific conclusions. Since Disability-Free Procreation is a more exact expression of the common and widely accepted disabilityfree intuition - the idea that rather than creating disabled children it is much better to create normal ones-our argument also questions what has been taken as common sense, thereby complementing existing critiques of this intuition (Amundson 2005, Barnes 2014, 2016b). And given that the reasoning we have critiqued is perhaps the most plausible and common way in the bioethics literature to justify Disability-Free Procreation, the argument has relevance not only for existing philosophical discussions but for bioethics more generally.

Both the disability-free intuition and the more scholarly articulations of ideas and principles behind it reflect shortcomings in the basic epistemic and moral virtue of humility in the realm of disability. Philosophers and bioethicists seem no less hubristic about disability and well-being than others, and we further hypothesize that those professional shortcomings stem at least in part from the marginalized position of people with disabilities in the discipline of philosophy, both historically and at present. The call with which we began this paper-the call for readers to imagine whether they would choose to create a child with or without a disability and positing how 'most of you' would respond-in fact relies on that marginalization.

Our call for more collective humility here is made more poignant by the reminder that the devalued estimation of the quality of the lives of people with disabilities on purportedly objective grounds played a critical role in the eugenic targeting of disabled people in the past (Wilson and St. Pierre 2016). The move from Procreative Beneficence to its disability-specific derivatives relies on that same devaluation, devaluation which, we have argued, arises from epistemically troubled assumptions rather than the now robust literature on first-person reports of well-being from people with disabilities.

To be clear, while we do not think that Procreative Beneficence is itself eugenic in nature, we see the kind of disability hubris that it relies on to derive conclusions about disability and well-being as contributing to a eugenic view of disability as, primarily, something to be pitied, regretted, and eliminated (Garland-Thomson 2012). Part of 
reclaiming disability as human variation, rather than seeing it as essentially defective, is to challenge this underlying eliminativist logic and the conception of disability from which it derives (Barnes 2016b). The present paper is a small attempt to do just that within contemporary discussions that have come quickly to occupy a central place in philosophical admonitions about parental choice. ${ }^{6}$

\section{References}

Alexandrova, Anna 2017, A Philosophy for the Science of Well-Being (Oxford, New York: Oxford University Press).

Amundson, Ron 2005, 'Disability, Ideology, and Quality of Life', in

David Wasserman, Jerome Bickenbach and Robert Wachbroit (eds.), Quality of Life and Human Difference: Genetic Testing, Health Care, and Disability (Cambridge: Cambridge University Press).

Asch, Adrienne and David Wasserman 2005, 'Where Is the Sin in Synecdoche?: Prenatal Testing and the Parent-Child Relationship', in David Wasserman, Jerome Bickenbach and Robert Wachbroit (eds.), Quality of Life and Human Difference: Genetic Testing, Health Care, and Disability (Cambridge: Cambridge University Press).

Barnes, Elizabeth 2009a, 'Disability and Adaptive Preference', in Philosophical Perspectives 23(1):1-22.

2009b, 'Disability, Minority, and Difference', in Journal of Applied Philosophy 26(4):337-355.

- 2014, 'Valuing Disability, Causing Disability', in Ethics 125(1):88-113.

-2016a, 'Reply to Guy Kahane and Julian Savulescu', in Res Philosophica 93(1):295-309.

2016b, The Minority Body: A Theory of Disability, 1st edition

(Oxford, United Kingdom: Oxford University Press).

Benatar, David and David Wasserman 2015, Debating Procreation: Is It Wrong to Reproduce? (New York: Oxford University Press).

\footnotetext{
${ }^{6}$ For constructive feedback we're grateful to anonymous referees, John Nenniger, Jeremy Pober, Robert Streiffer, students in Matt Barker's 2015 course on the ethics of biotechnology at Concordia University, and the audience at the Canadian Philosophical Annual (CPA) Congress 2015 in Ottawa where we presented an earlier version of this paper. We also gratefully acknowledge the support of the Community-University Research Alliance program of the Social Sciences and Humanities Research Council of Canada for their financial support for the Living Archives on Eugenics in Western Canada project (2010-2016).
} 
Boyd, Richard 1999, 'Homeostasis, Species, and Higher Taxa', in Robert A. Wilson (ed.), Species: New Interdisciplinary Essays (Cambridge, MA: MIT Press).

Brock, Dan W. 1993, Life and Death: Philosophical Essays in Biomedical Ethics (Cambridge: Cambridge University Press).

- 1995, 'Justice and the ADA: Does Prioritizing and Rationing Health Care Discriminate against the Disabled?', in Social Philosophy and Policy 12(2):159-185.

2005, 'Preventing Genetically Transmitted Disabilities While Respecting Persons with Disabilities', in David Wasserman, Jerome Bickenbach and Robert Wachbroit (eds.), Quality of Life and Human Difference: Genetic Testing, Health Care, and Disability (Cambridge: Cambridge University Press).

Camfield, Laura and Suzanne M. Skevington 2008, 'On Subjective Well-Being and Quality of Life', in Journal of Health Psychology 13(6):764-75.

Crisp, Roger 2014, 'Well-Being', in The Stanford Encyclopedia of Philosophy <http://plato.stanford.edu/archives/win2014/entries/ well-being/ $>$.

Diener, Ed 1984, 'Subjective Well-Being', in Psychological Bulletin 95:542-75.

Domellöf, Erik, Ludmilla Hedlund and Pia Ödman 2013, 'HealthRelated Quality of Life of Children and Adolescents with Functional Disabilities in a Northern Swedish County', in Quality of Life Research 23(6):1877-82.

Endermann, Michael 2013, 'Predictors of Health-Related and Global Quality of Life among Young Adults with Difficult-to-Treat Epilepsy and Mild Intellectual Disability', in Epilepsy \& Behavior 26(2):188-95.

Fellinghauer, Bernd, Jan D. Reinhardt, Gerold Stucki and Jerome Bickenbach 2012, 'Explaining the Disability Paradox: A Cross-Sectional Analysis of the Swiss General Population', in BMC Public Health 12:655.

Fuhrer, Marcus J., Diana H. Rintala, Karen A. Hart, Rebecca Clearman and Mary Ellen Young 1992, 'Relationship of Life Satisfaction to Impairment, Disability, and Handicap among Persons with Spinal Cord Injury Living in the Community', in Archives of Physical Medicine and Rehabilitation 73(6):552-7.

Garland-Thomson, Rosemarie 2012, 'The Case for Conserving Disability', in Journal of Bioethical Inquiry 9(3):339-55. 
Gavelova, Miriam, Iveta Nagyova, Jaroslav Rosenberger, Martina Krokavcova, Berrie Middel, Zuzana Gdovinova, Johan

W. Groothoff and Jitse P. van Dijk 2015, 'Importance of an Individual's Evaluation of Functional Status for Health-Related Quality of Life in Patients with Multiple Sclerosis', in Disability and Health Journal 8(3):372-9.

Glover, Jonathan 2008, Choosing Children: Genes, Disability, and Design (Oxford; New York: Oxford University Press).

Goering, Sara 2008, "'You Say You're Happy, But...": Contested

Quality of Life Judgments in Bioethics and Disability Studies', in Journal of Bioethical Inquiry 5(2/3):125-35.

Gow, Alan J., Martha C. Whiteman, Alison Pattie, Lawrence Whalley, John Starr and Ian J. Deary 2005, 'Lifetime Intellectual Function and Satisfaction with Life in Old Age: Longitudinal Cohort Study', in British Medical Journal 331(7509):141-2.

Herissone-Kelly, P. 2006, 'Procreative Beneficence and the Prospective Parent', in Journal of Medical Ethics 32(3):166-9.

Kahane, Guy and Julian Savulescu 2009, 'The Welfarist Account of Disability', in Kimberley Brownlee and Adam Cureton (eds.), Disability and Disadvantage (Oxford: Oxford University Press). -2016, 'Disability and Mere Difference', in Ethics 126(3):774-88.

Kent, Deborah 2000, 'Somewhere a Mockingbird', in Erik Parens and Adrienne Asch (eds.), Prenatal Testing and Disability Rights (Washington, DC: Georgetown University Press).

Kitcher, Philip 1997, The Lives to Come (New York: Simon and Schuster).

Lawton, M. Powell 1984, 'Investigating Health and Subjective WellBeing: Substantive Challenges', in The International Journal of Aging and Human Development 19(2):157-66.

Lucas, Richard E. 2007, 'Long-Term Disability Is Associated with Lasting Changes in Subjective Well-Being: Evidence from Two Nationally Representative Longitudinal Studies', in Journal of Personality and Social Psychology 92(4):717-30.

Lucas, Richard E., Andrew E. Clark ,Yannis Georgellis and Ed Diener 2003, 'Reexamining Adaptation and the Set Point Model of Happiness: Reactions to Changes in Marital Status', in Journal of Personality and Social Psychology 84(3):527-39.

McMahan, Jeff 2005, 'Causing Disabled People to Exist and Causing People to Be Disabled', in Ethics 116(1):77-99. 
Mehnert, Thomas, Herbert H. Krauss, Rosemary Nadler and Mary Boyd 1990, 'Correlates of Life Satisfaction in Those with Disabling Conditions', in Rehabilitation Psychology 35(1):3-17.

Moller, Dan 2011, 'Wealth, Disability, and Happiness', in Philosophy \& Public Affairs 39(2):177-206.

Nagi, Saad Z. 1976, 'An Epidemiology of Disability among Adults in the United States', in The Milbank Memorial Fund Quarterly. Health and Society 54(4):439-67.

Nussbaum, Martha C. 2001, Women and Human Development: The Capabilities Approach (Cambridge: Cambridge University Press). 2009, Frontiers of Justice: Disability, Nationality, Species Membership (Cambridge, MA: Harvard University Press).

Padua, Luca, Claudia Rendeli, Alessia Rabini, Elisabetta Girardi, Pietro Tonali and Elio Salvaggio 2002, 'Health-Related Quality of Life and Disability in Young Patients with Spina Bifida', in Archives of Physical Medicine and Rehabilitation 83(10):1384-8.

Pagán-Rodríguez, Ricardo 2010, 'Onset of Disability and Life Satisfaction: Evidence from the German Socio-Economic Panel', in The European Journal of Health Economics 11(5):471-85.

Parens, Erik and Adrienne Asch 1999, 'Special Supplement: The Disability Rights Critique of Prenatal Genetic Testing Reflections and Recommendations', in The Hastings Center Report 29(5):S1-22.

Parfit, Derek 1987, Reasons and Persons, reprinted with corrections (Oxford: Oxford University Press).

Powdthavee, Nattavudh 2009, 'What Happens to People before and after Disability? Focusing Effects, Lead Effects, and Adaptation in Different Areas of Life', in Social Science \& Medicine 69(12):1834-44.

Savulescu, Julian 2001, 'Procreative Beneficence: Why We Should Select the Best Children', in Bioethics 15(5-6):413-26.

-2007, 'In Defence of Procreative Beneficence', in Journal of Medical Ethics 33(5):279-83.

2008, 'Procreative Beneficence: Reasons to Not Have Disabled Children', in Skene Loane and Janna Thompson (eds.), The Sorting Society (Cambridge: Cambridge University Press).

Savulescu, Julian and Guy Kahane 2009, 'The Moral Obligation to Create Children with the Best Chance of the Best Life', in Bioethics 23(5):274-90.

2011, 'Disability: A Welfarist Approach', in Clinical Ethics $6(1): 45-51$. 
Singer, Peter A. 2001, 'Response to Mark Kuczewski', in The American Journal of Bioethics 1(3):55-56.

Sparrow, Robert 2008, 'Genes, Identity and the "Expressivist Critique", in Loane Skene and Janna Thompson (eds.), The Sorting Society (Cambridge: Cambridge University Press).

Stensman, R. 1985, 'Severely Mobility-Disabled People Assess the Quality of Their Lives', in Scandinavian Journal of Rehabilitation Medicine 17(2):87-99.

Stock, William A., Morris A. Okun and Mary Benin 1986, 'Structure of Subjective Well-Being among the Elderly', in Psychology and Aging 1(2):91-102.

Ubel, Peter A., George Loewenstein, Norbert Schwarz and Dylan Smith 2005, 'Misimagining the Unimaginable: The Disability Paradox and Health Care Decision Making', in Health Psychology 24(4 Suppl):S57-62.

Wasserman, David, Adrienne Asch, Jeffrey Blustein and Daniel Putnam 2016, 'Disability: Health, Well-Being, and Personal Relationships', in The Stanford Encyclopedia of Philosophy <http://plato.stanford.edu/archives/spr2016/entries/ disability-health/>.

Wilson, Robert A. and Joshua St. Pierre 2016, 'Eugenics and Disability', in Patrick Devlieger, Beatriz Mirandaa-Galarza, Steven E. Brown and Megan Strickfaden (eds.), Rethinking Disability: World Perspectives in Culture and Society (Antwerp: Garant Publishing).

World Health Organization (WHO) 1980, 'International Classification of Impairments, Disabilities, and Handicaps: A Manual of Classification Relating to the Consequences of Disease', Published in accordance with resolution WHA29.35 of the Twenty-ninth World Health Assembly, May 1976. (1980) (Geneva, Switzerland). 